\title{
A Tariff for Reactive Power
}

\author{
Christopher Tufon, Alan Isemonger, Brendan Kirby, Senior Member, John Kueck, Senior Member, \\ and Fangxing Li, Senior Member
}

\begin{abstract}
This paper describes a suggested tariff or payment for the local supply of reactive power from distributed energy resources. The authors consider four sample customers, and estimate the cost of supply of reactive power for each customer. The power system savings from the local supply of reactive power are also estimated for a hypothetical circuit. It is found that reactive power for local voltage regulation could be supplied to the distribution system economically by customers when new inverters are installed. The inverter would be supplied with a power factor of 0.8 , and would be capable of local voltage regulation to a schedule supplied by the utility. Inverters are now installed with photovoltaic systems, fuel cells and microturbines, and adjustable-speed motor drives.
\end{abstract}

Index Terms-Inverter, Power Factor, Reactive Power, Tariff, Voltage Regulation.

\section{INTRODUCTION}

This paper is a brief summary of a longer and more thorough report by the authors [1]. The authors assessed the ability of four PG\&E customers to supply dynamic reactive power for local voltage regulation. Supply costs and value are estimated, and a sample tariff is proposed.

Reactive power supply is essential for the reliable operation of the bulk power system. Reactive power flows when current leads or lags behind voltage (Fig. 1). Typically, the current in a distribution system lags behind voltage because of inductive loads such as motors and transformers. Reactive power flow wastes energy and capacity and causes voltage droop. To correct lagging power flow, leading reactive power (current leading voltage) is supplied to bring the current into phase with voltage. When the current is in phase with voltage, system losses are reduced, system capacity is increased, and voltage rises.

Reactive power can be supplied from either static or dynamic sources. Capacitors are static sources of reactive power and are typically installed on the transmission and distribution system. They are "static" in the sense that they do not provide active voltage control; their output varies with the square of the voltage. Dynamic reactive power can be

This work was supported in by the U.S. Department of Energy, Office of Electricity and Energy Reliability

C. Tufon is with Pacific Gas \& Electric Company, San Francisco, CA, 94102, USA, (email: czt1@pge.com).

A. Isemonger is with the California Independent System Operator, Folsom, CA, 95630, USA

B. Kirby is with Oak Ridge National Laboratory, Knowledge Preservation Program, Oak Ridge, TN, 37830, USA

J. Kueck is with Oak Ridge National Laboratory, Oak Ridge, TN, 37830, USA

F. F. Li is with the University of Tennessee, Knoxville, TN, 37996, USA supplied by generators and by transmission equipment such as synchronous condensers and static VAR (volt amp reactive) compensators (SVCs) at substations ${ }^{1}$. SVC and capacitor costs have historically been included in the revenue requirement of the transmission or distribution system operator and recovered through cost-of-service rates. By contrast, conventional generator costs are typically recovered through the energy market. Dynamic sources at the distribution level, while more costly, would be very useful in helping to regulate local voltage. Local voltage regulation would reduce system losses, increase circuit capacity, increase reliability, and improve efficiency. Reactive power is theoretically available from any inverter-based equipment such as photovoltaic (PV) systems, fuel cells, microturbines, and adjustable-speed drives. However, the installation is usually only economical if reactive power supply is considered during the design and construction phase.

In this report, we find that if the inverters of PV systems or the generators of combined heat and power (CHP) systems were designed with capability to do so, they could supply dynamic reactive power economically. On an annualized basis, these inverters and generators may be able to supply dynamic reactive power for an annualized cost of about $\$ 5$ or $\$ 6$ per kVAR. The savings from the local supply of dynamic reactive power would be in reduced losses, increased capacity, and decreased transmission congestion. The net savings are estimated to be about \$7 per kVAR on an annualized basis for a hypothetical circuit.

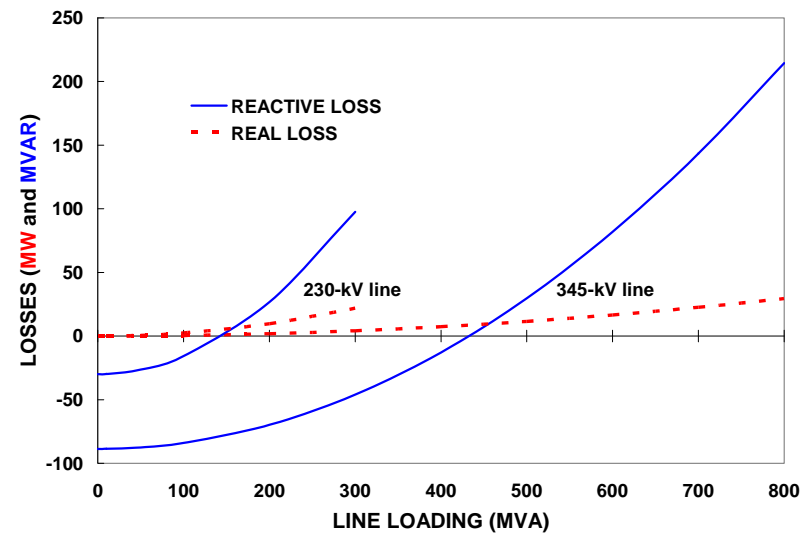

Fig. 1. Transmission lines supply reactive power to the system when lightly loaded but absorb reactive power when heavily loaded.

${ }^{1}$ The SVC name can be confusing. The device provides fast, accurate, control of dynamic reactive power. The term "static" in the name static var compensator refers to the fact that it is a solid state device with no rotating parts as would be found in a generator. 
Thus the distribution company could economically purchase a dynamic reactive power service from customers for perhaps $\$ 6 / \mathrm{kVAR}$. This practice would provide for better voltage regulation in the distribution system and would provide an alternate revenue source to help amortize the cost of PV and CHP installations.

\section{A. The Growing Need for Dynamic Reactive Power and for a Tariff}

A reactive power supply tariff could encourage the use of dynamic VAR sources in a distribution system by allowing capable loads and distributed energy to participate in the supply of reactive power at a cost less than the value of the provided service. The authors estimate this value by summing the distribution savings due to reduced losses, increased circuit capacity, and increased margin to voltage collapse.

Opportunities are available to supply reactive power from any inverter-based equipment such as PV systems, fuel cells, microturbines, and adjustable-speed drives. Opportunities are also available from engine generators. The window of opportunity lies in the design and specification stage. The benefits that a reactive tariff can provide will be realized slowly as industrial processes and machinery change, provided the incentive is there. There are two possible venues for a tariff to motivate the modification of a load in the design phase, namely through the system operator if the customer is large enough and the regulations allow it, and through the load-serving entity, should that customer choose not to connect directly to the system operator.

Dynamic reactive power may be provided by devices in the categories described as follows.

\section{1) Engine Generators}

Engine generators in Combined Heat and Power (CHP) applications are often designed to run continuously. Engine generators are typically supplied with generators that have a power factor of 0.9 lag to 0.95 lead, or wider.

\section{2) Fuel Cells, PV Systems, and Microturbines}

These power sources are all equipped with inverters, but the inverters are often designed to operate at 1.0 power factor. The power sources could be purchased, however, with inverters capable of operating at 0.8 power factor at perhaps a $10 \%$ higher cost. Because the inverter itself is usually less than $25 \%$ of the cost of the entire installation, supplying an inverter with the capability to supply reactive power would increase the cost of the entire fuel cell or PV installation by only about 2 or $3 \%$.

Transmission System Based Reactive Power Source Devices on the transmission system can supply both "static" and "dynamic" reactive power. Static reactive power sources are devices such as capacitors and inductors with fixed impedances. They provide the power system with a fixed, and uncontrolled, amount of reactive support (though it does vary with the square of the voltage). Dynamic reactive power sources provide active control of reactive power and voltage. Synchronous condensers are an older technology similar to a generator without a turbine or engine to drive it. The technology is seeing renewed interest with the advent of superconducting machines. Static VAR compensators and STATCOMs are solid state devices (hence the "static" in their names, an unfortunate confusion with static reactive power) which provide dynamic reactive power.

Transmission system reactive power device costs have historically been included in the revenue requirement of the transmission owner and recovered through cost-of-service rates. Capacitors themselves are inexpensive, but the associated switches, control, and communications, and their maintenance, can amount to as much as one-third of the total operations and maintenance budget of a distribution system. SVCs and synchronous condensers are fairly expensive devices with significant maintenance costs.

\section{B. Reactive Power Sinks}

Reactive power absorption occurs when current flows through an inductance. Inductance is found in transmission lines, transformers, and induction motors. The reactive power absorbed by a transmission line or transformer is proportional to the square of the current. A transmission line also has capacitance. When a small amount of current is flowing, the capacitance dominates, and the lines have a net capacitive effect which raises voltage. This happens at night when current flows are low. During the day, when current flow is high, the square of the current times the transmission line inductance means that there is a large inductive effect, greater than the capacitance, and the voltage sags.

\section{Voltage Control}

Voltage control and reactive power management are two aspects of a single activity that both supports reliability and facilitates commercial transactions across transmission networks. Controlling (or minimizing) reactive power flow can reduce losses and congestion on the transmission system. On an ac power system, voltage is controlled by managing production and absorption of reactive power.

Taken together, these two factors result in a dynamic reactive power requirement. The loss of a generator or a major transmission line can have the compounding effect of reducing the reactive supply and, at the same time, reconfiguring flows such that the system is consuming additional reactive power. At least a portion of the reactive supply must be capable of responding quickly to changing reactive power demands and maintaining acceptable voltages throughout the system. Thus, just as an electrical system requires real power reserves to respond to contingencies, so must it also maintain dynamic reactive power reserves. Transmission line capacity is sometimes limited by voltage support, as shown in Figure 2.

There are two significant differences between the real and reactive services. First, real power can be delivered over much greater distances so the supplying resources are not as constrained by location, whereas reactive resources must be distributed throughout the power system. Second, generation of real power requires the conversion from some other energy 


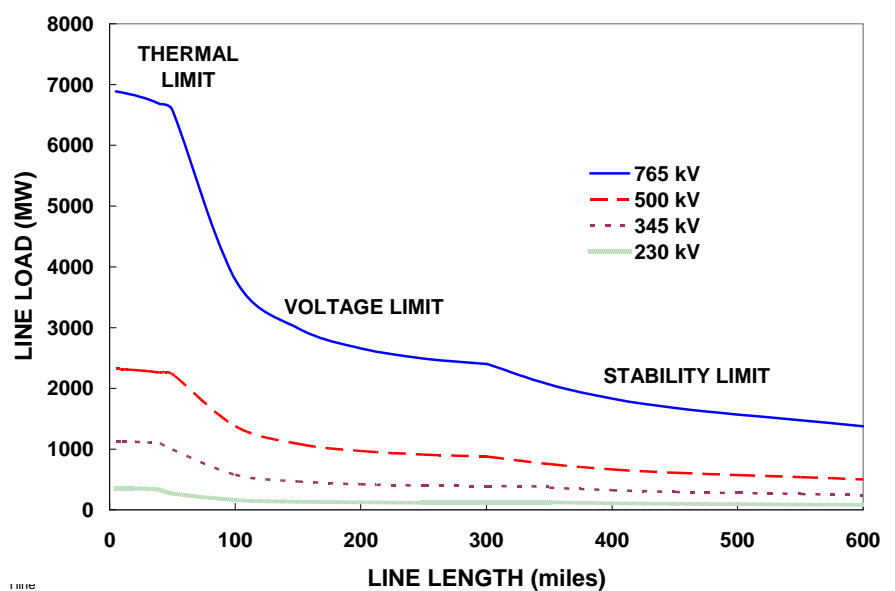

'Fig. 2. Transmission line capacity is limited by thermal capability, voltage support, or stability concerns, depending on the line length.

resources, such as chemical or nuclear fuel, sunlight, or a mechanical resource such as wind or water flow, whereas producing reactive power simply requires changing the angle between voltage and current.

At the local (distribution) level, the customers do not have sufficient information about the configuration of the transmission system or the actions of other customers to know ahead of time what reactive power requirements will result from their choices. However, customers could be provided with a voltage schedule that would guide them in the production of local reactive power. The voltage schedule would simply tell the customer what local voltage to maintain based on the time of day. The customer would supply or absorb reactive power, to the extent of his capability, to meet the schedule.

The cost for reactive power support varies dramatically depending on the device employed (Fig. 2). Capacitors and inductors are relatively inexpensive, but they are typically slow to respond and they are deployed in discrete steps [2].

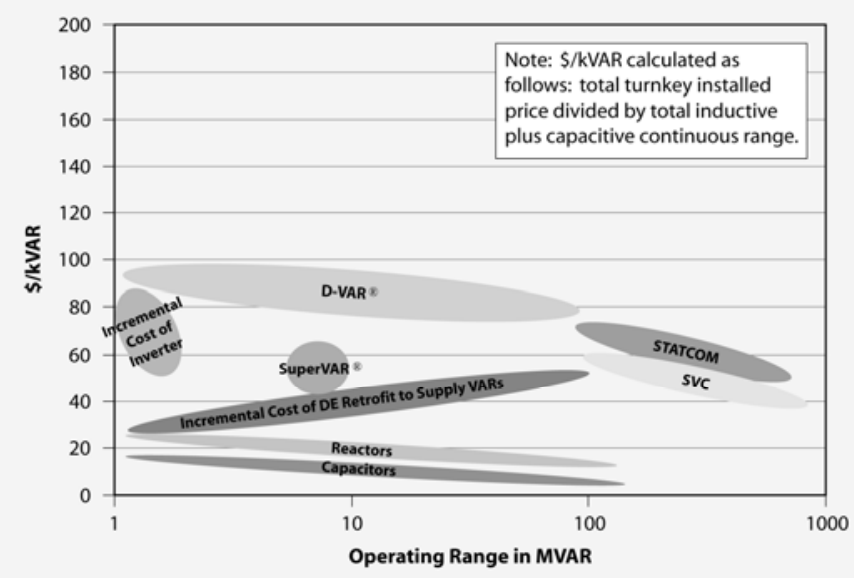

Fig. 3. Average costs of reactive power technologies.

Generators, synchronous condensers, and static VAR compensators (SVCs) respond quickly and accurately, but they are expensive. Dynamic reserves such as SVCs are usually only used on the transmission system level when there is a problem such as a large load swing due to a steel mill, or a contingency such as a line outage, that cannot be handled with local generation or switching in other lines. We believe that the incremental cost of a larger inverter, however, may now be economical for the supply of local dynamic reactive power to reduce distribution system losses and release capacity.

\section{1) Use of an Inverter}

Inverters supplied with PV systems, adjustable-speed drives, microturbines, and active power filters can be used to supply dynamic reactive power if they are appropriately controlled. Also, the inverter would need to be capable of carrying the extra current. Typically, a power factor of 0.8 would be adequate.

\section{Estimated Costs for Four Customers to Supply Reactive Power}

Four customers were assessed for their potential to supply reactive power. An informal estimate was also made of the cost to the customer for modifications to supply reactive power in accordance with a voltage schedule. The four customers are a shopping center, a conventional generating station (which is presently supplying reactive power in accordance with a voltage schedule), an urban university campus, and a steel-rolling mill. As expected, these cases show that installing voltage control capability when the customer's electrical distribution system is built is considerably less expensive than retrofitting it later.

\section{1) Shopping Center}

The first example customer is an urban shopping mall with approximately a 2-MW load that normally operates at 0.9 lagging power factor. We considered modifications necessary to enable the mall to control its power factor up to a level of 0.95 leading in response to a voltage schedule supplied by the distribution utility.

One possible source for dynamic reactive power, and a modification that would also improve the efficiency of the shopping center's air conditioning, is to install variablefrequency motor drives with a common rectifier that has an active front end. The active front end enables the rectifier to control the power factor of the power it is drawing. We estimate about $\$ 19 / \mathrm{kVAR}$ annual capacity cost to provide the dynamic reactive capability at the shopping center. As we will see in later examples, this is a relatively high cost. This example demonstrates the economic need to install the dynamic reactive capability when the adjustable-speed-drive system is installed rather than retrofitting later.

\section{2) Steel-Rolling Mill}

S\&C Electric performed an evaluation of reactive power demand for a steel-rolling mill and provided a brief report on potential solutions. The reactive power flow to the mill was between $900 \mathrm{kVAr}$ and $1650 \mathrm{kVAr}$. Power factor varied from 0.5 to 0.9 lagging. The real power supplied to the mill varies rapidly from about $1 \mathrm{MW}$ to $2 \mathrm{MW}$. S\&C Electric determined that the power factor could be corrected and made to go to 
0.95 leading by using a 2500-kVAR Pure Wave adaptive VAR compensator (AVC) system. Using the 20-year life of the AVC, the annualized cost would be about $\$ 20 / \mathrm{kVAR}$.

The AVC uses discrete steps of thyristor switched capacitors to supply reactive compensation on a cycle by cycle basis. The AVC would measure the reactive portion of load current and then match the lagging current by switching in the proper number of capacitor stages. This can be done on a perphase basis, which would work best for an unbalanced load like the rolling mill.

\section{3) University with PV Inverter with Active Front End}

The PV inverter under consideration has a rated output of $0.5 \mathrm{MW}$ and 1.0 Power Factor. We would need a 0.8 power factor, giving us 0.625 MVA. Fig. 4 shows us the extra kVAR that are available. We will assume that this inverter has a cost of $\$ 543$ per $\mathrm{kVA}$. We estimate the total incremental cost to the university on an annualized basis for supplying dynamic reactive power is then $\$ 6 / \mathrm{kVAR}$.

The university also has an engine generator that is presently used in voltage regulation service with Pacific Gas and Electric (PG\&E). The generator field is controlled to regulate voltage to a schedule supplied by PG\&E. What if the generator had been oversized when it was originally purchased so that it could carry additional current to supply more reactive power? We estimate an annualized cost to the customer of $\$ 4.9$ per kVAR for supplying reactive power from the generator.

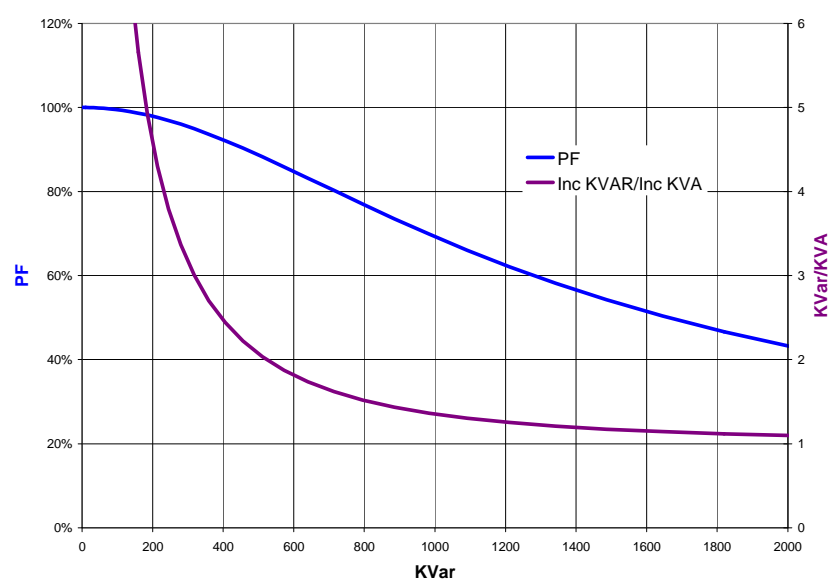

Fig. 4. Change in kVAR/kVA as power factor is reduced.

\section{E. Value of Reactive Supply at the Distribution Level, Subtransmission, and Grid}

As a first step in estimating the value of voltage support, it would be reasonable to simply average the gross (transmission-level) payments that are presently being used by various transmission system operators around the country. FERC 2005, Table 9, [4] provides the effective gross support rate in \$/MVAR-year for 22 locations. The average annualized rate is about $\$ 4.5 / \mathrm{kVAR}$. This provides a useful figure for the basic value of voltage support at the transmission level, but we believe that the value of voltage support at the load is significantly higher. At the load, one must also take into consideration the reduction of losses in the distribution system and the increased capacity of the transmission system. We estimate these values using the following examples [2]

\section{1) Reduced Losses Due to Reactive Support at the Load}

In a simple system, there is a generation bus, a load bus, and a line connecting the two buses. Injection of reactive power at the receiving end may raise the voltage and reduce the line current. Since the real power loss is $I^{2} R$, the loss will be reduced if the current is reduced with the assumption that the load-side voltage remains the same. The actual reduction of power loss is estimated as follows. The savings due to reduced losses are $\$ 111$ divided by 156 kVAR, or \$0.71/kVAR-year.

\section{2) Increased Line Capacity (Thermal Limit)}

If the injection of reactive power lifts a 0.9 lagging power factor at the load side to 0.95 power factor, the line flow will be reduced significantly. This is equivalent to having a distribution or transmission line with bigger KVA capacity rating. The saved line capacity may be converted to savings for importing more inexpensive power from this line, compared with dispatching expensive local units in the load pocket. We estimate the savings per MVAR-year will be \$1200/MVAR-year, or \$1.20/kVAR-year.

Typically, the entity that benefits from this category is the utility and/or transmission company, since they own the networks.

\section{3) Increased Maximum Transfer Capability (Stability Limit)}

The maximum transfer capability of the sample system is given as

$$
P_{\max }=\frac{E^{2}\left(-k+\sqrt{1+k^{2}}\right)}{2 X} \text { where } E=V \text { and } k=\frac{Q}{P}
$$

Again, assuming the compensation lifts the power factor from 0.9 to 0.95 , it can be easily verified that the maximum transfer capacity has been improved by $15.5 \%$. Therefore, during the four months of peak load, the system may move 15.5\% more inexpensive MW from generation center to load center while keeping roughly the same voltage stability margin. Again, this can be converted to a dollar savings of about \$3.58/kVAR-year. The entity that benefits in this case is the utility and/or transmission company, since they are the network owners. For every 1 MVAR local compensation, the local VAR loss within the PG\&E transmission system will be reduced by $x$ MVAR. Then, the reduced VAR in the tie-line will increase the real power transfer in the same tie-line, because the present limit is the VAR limit. The room left in the tie-line VAR can be then used by MW flow. We estimate a benefit of $\$ 30.97 / \mathrm{kVar}$-year. This value must be corrected, 
however, to account for only 120 peak days per year, and hours per day of peak time: $(120 \times 6) / 8760$ is 0.083 , which then gives a corrected value of $\$ 2.57 / \mathrm{kVAR}$-year for the total economic benefit.

\section{4) Conventional Generator}

This conventional generator has two gas turbine generators, one of which is normally operating and regulating bus voltage in accordance with a voltage schedule. The generator is not required to sacrifice real power production in order to produce reactive power to support voltage. The generators are run based on market conditions and their bid price for energy. Because the generators are required by contract to be capable of operation from 0.9 lag to 0.95 leading, the only additional cost in operating them through this range is the additional $I^{2} R$ cost and other losses associated with current flow in the generator windings and operation of the exciter. There are various methods for calculating this cost to the generator operator, but a reasonable guess of the upper limit to this cost can be derived from the payments that system operators provide to generators for reactive support. These range from about $\$ 1$ to $\$ 4$ for each kVAR of capacity paid annually. Reactive support from large generators is inexpensive, but as discussed earlier, it is often in the wrong place, and does not travel well. In the CAISO reactive support from generators is just considered a cost of doing business and is not charged separately [3].

\section{TARIFF StRATEgIES TO MOTIVATE CUSTOMERS TO SUPPLY REACTIVE SUPPORT}

The value of providing dynamic reactive supply from load was found in our hypothetical distribution circuit to be $\$ 2.57 / \mathrm{kVAR}$-year. To find the total value of local reactive power supply we add this value to the gross voltage support rate. The average gross voltage support rate was found by a survey [4] to be about $\$ 4.50 / \mathrm{kVAR}$-year. The total value including reduced losses, impact to net import, and voltage support service is then about $\$ 7 / \mathrm{kVAR}$-year.

The estimated capacity costs of supplying reactive power are summarized in Table I.

\section{A. A Suggested Tariff}

FERC staff produced a report on the supply of reactive power [4]. The report might be described as comprehensive and exhaustive, but it is not definitive in that it does not produce a simple prescription as to what FERC and interested market participants think should happen with respect to voltage support. The nature of voltage support is sufficiently complex that easy answers are hard to find. The FERC report starts by asserting that there should be no undue discrimination in remuneration. The FERC report suggests that the payment for reactive power could be divided into two different parts, basically a capacity payment and a real-time payment for actual production. The marginal cost of production of reactive power within a generator's D-curve is near zero and the value of dynamic reactive reserves is so high. As a general rule, payment schemes that have been adopted throughout the country place any incentive (and the capital cost recovery) for providing reactive capability into the capacity payment.

If we select a payment to be made to the customer which is chosen to be at the midpoint between the customer's cost for supplying reactive power and the total economic benefit, a problem can arise. What if too many customers on a circuit or in a particular area begin to supply dynamic reactive power for the economic benefit of an incentive payment or a rate reduction? The first customers would be providing a needed service that has a value larger than the payment determined in tariff design, but when enough of them are connected and supplying reactive power to meet the need, connecting additional customers would not provide any more savings or

TABLE I. ANNUAL CAPACITY COSTS TO EXAMPLE CUSTOMERS AND CONVENTIONAL DISTRIBUTION SYSTEM FOR THE SUPPLY OF REACTIVE POWER (FROM REF. 4)

\begin{tabular}{ll}
\hline \multicolumn{1}{c}{ Customer } & \multicolumn{1}{c}{ Cost } \\
\hline Shopping center & $\begin{array}{l}\text { \$19/kVAR (active front end on adjustable- } \\
\text { speed drives) } \\
\text { \$5/kVAR (oversizing the generator on the } \\
\text { engine generator) } \\
\text { University }\end{array}$ \\
$\begin{array}{l}\text { \$6/kVAR (oversizing the PV inverter) } \\
\text { Steel-rolling mill }\end{array}$ & $\begin{array}{l}\text { \$20/kVAR (S and C Pure Wave AVC system) } \\
\text { Conventional }\end{array}$ \\
\hline
\end{tabular}

congestion reduction. The additional customers should not be paid the same amount. There are two possible solutions. One would be to have a local market for reactive power, and the second solution would be to assess the local need when the customer applies, if the local need exists, and give him a rate he can depend on for 20 years to amortize his equipment cost. The latter option would be practical only if a blanket rate was developed that was applicable to the hundreds of transmission and distribution planning areas in a large UDC.

The first solution, a local market for reactive power, would be impractical for several reasons: (1) Reactive power does not travel well and the zones would have to be quite small, requiring a great deal of computation and complexity; (2) market power issues would prevent operating a market if too few customers offered to supply reactive power simultaneously; and (3) the average small customer probably is not interested in or capable of participating in a market, especially one that requires the customer to reset the power factor control on a PV inverter or the excitation on a generator every day.

The second solution, assessing the local need for reactive supply when the customer applies for connection, and then developing a long-term contract with the customer, could be done with engineering guidelines and would not require expensive engineering analysis on each circuit. If adequate dynamic reactive reserves already exist in an area, more need not be purchased. If dynamic reactive reserves are needed, 
they can be contracted for at the fixed rate that is known to be economical for the distribution system operator, but which will still be above the cost of supply for the customer, and will help amortize the cost of a PV or CHP system.

The total value for local dynamic reactive supply, as estimated above, is about $\$ 7 / \mathrm{kVAR}$ on an annualized basis. This includes reduced losses, increased transmission capacity, and increased transfer. (Note that these estimates do not include the value of expanded margin to distribution voltage collapse or power quality. However, assessment of these issues and a recommendation method for determining the value of local reactive supply to correct it are beyond the scope of this paper.)

The customer's cost in supplying dynamic reactive power ranges from about $\$ 5$ to $\$ 20 / \mathrm{kVAR}$, annualized. The price that is paid must be reasonable for both the customer and the Utility Distribution Company (UDC). We suggest a figure of $\$ 6 / \mathrm{kVAR}$ as appropriate compensation. We believe that if such a tariff were put into practice, each distribution company that wished to use it would do a calculation similar to the one above to determine the value of dynamic reactive support in their circuits. Again, as mentioned above, they would only be required to contract for the amount they needed in a particular circuit. The customers who could profitably supply dynamic reactive power for this amount would then have a new revenue source to amortize their distributed energy investment. The customer and distribution company would also enjoy improved power quality and tighter voltage regulation - another benefit we have not attempted to quantify.

\section{B. The Suggested Tariff Applied to Four Sample Customers}

\section{1) Shopping Center}

We found that the cost of dynamic reactive supply from the shopping center, accomplished by retrofitting adjustable-speed drives with an active front end, to be about \$19/kVAR on an annualized basis. Clearly, this modification would not be economical for the sole purpose of providing the service of dynamic reactive supply.

\section{2) University}

We found that the total cost to the university on an annualized basis for supplying dynamic reactive power from a new PV inverter, if we consider only the additional cost of oversizing the inverter, is about $\$ 6 / \mathrm{kVAR}$ on an annualized basis. The annualized cost for supplying reactive power from an oversized generator is about $\$ 5 / \mathrm{kVAR}$. Either of these options look attractive. Most importantly, the PV installation would then have an additional revenue stream of $\$ 6 \times 2 \times 365$ kVAR, or $\$ 4500$ per year. The factor of 2 comes from the inverter's capability to be leading or lagging.

\section{3) Steel-Rolling Mill}

A steel-rolling mill has a power factor that varies from 0.9 to 0.5 lagging. The system which could be used to correct the rapidly fluctuating power factor is a "Pure Wave" static VAR compensator sold by S\&C Electric. The annualized cost of the correction from this system is about $\$ 20 / \mathrm{kVAR}$. This modification would not be economical from the viewpoint of providing reactive power, but the compensator would provide improved power quality at the mill, improve distribution system efficiency, and avoid any power factor penalty.

\section{4) Conventional Generator}

The fourth customer, a conventional generator, is presently not required to go outside of its performance curve when performing voltage regulation, so lost opportunity to generate and sell power due to reactive support is not an issue. The generator is required to meet the voltage schedule as a condition of connection. The costs of exciter operation, generator losses, etc., are factored into their bid for energy. Based on a check with this one customer, the market system appears to be working well at the transmission level for reactive reserves and voltage support. At this time, we do not see a need for a special tariff for generators connected at the transmission level.

\section{CONCLUSION}

The value of reactive power supplied by the customer has been estimated to be about $\$ 7 / \mathrm{kVAR}$ on an annualized basis. This includes the value of reduced losses, released transmission capacity, and increased transfer capability, as determined using a hypothetical distribution circuit. This does not include the value of increased margin to voltage collapse, because for many utilities voltage collapse is not an issue at this time. The customer's cost of providing reactive power ranges from $\$ 5$ to $\$ 20 / \mathrm{kVAR}$ on an annualized basis depending on the type of technology used.

\section{REFERENCES}

[1] C. Tufon, A. Isemonger, B. Kirby, J. Kueck, and F. F. Li, “A Tariff for Reactive Power," Oak Ridge National Laboratory, Oak Ridge, TN, ORNL/TM-2008/083, July 2008.

[2] F. F. Li, J. Kueck, T. Rizy, and T. King, "A Preliminary Analysis of the Economics of Using Distributed Energy as a Source of Reactive Power Supply,” Oak Ridge National Laboratory, Oak Ridge, TN, ORNL/TM2006/14, 2006.

[3] CAISO Tariff http://www.caiso.com/1c0b/1c0ba7d5353c0.pdf, Original Sheet 78, page 95 .

[4] "Principles for Efficient and Reliable Reactive Power Supply and Consumption, Staff Report, Docket No. AD05-1-000, February 4, 2005”

\section{BIOGRAPHIES}

John Kueck earned a BS in Physics from Purdue University and an MS in Electrical Engineering - Power Systems, from Ohio State University. Over the first 20 years of his career, Mr. Kueck worked in the design and operation of fossil fuel and nuclear generating stations. From 1992 to present, Mr. Kueck has been a researcher at the Oak Ridge National Laboratory (ORNL). He has developed the Distributed Energy Controls and Communication Lab at ORNL. His major interest is the local supply of reactive power from distributed energy resources as a reliability service.

Brendan Kirby is a private consultant with numerous clients including AWEA, Oak Ridge National Laboratory, EPRI and others. He recently retired as a senior researcher with the Oak Ridge National Laboratory Power Systems Research Program. He has 33 years of electric utility experience and has published over 120 papers, articles, and reports on ancillary services, wind integration, restructuring, the use of responsive load as a bulk system 
reliability resource, and power system reliability. Publications are available at www.consultkirby.com

Alan G. Isemonger has worked as an energy economist for the past eight years, and most recently at the California ISO, where he is the Manager of Market Information. He holds a M.A. in Economics from Leeds University in the United Kingdom. The views expressed in this article are solely those of the author and do not represent those of the California ISO or any of its market participants. Any errors remain solely the responsibility of the author. He can be contacted at isemonge@yahoo.com.

Chris Tufon is currently a senior tariff analyst at Pacific Gas and Electric Company (PG\&E) in San Francisco. He holds a bachelors degree in mechanical engineering and a masters in chemistry from Brigham Young University Provo, Utah and California State University, Fresno. He has developed rate solutions for issues relating to interconnection and implementation of DG resources at PG\&E, including revising how PG\&E bills its customers for reactive power.

Fangxing (Fran) Li (M ‘01, SM '05) received his BSEE and MSEE degrees from Southeast University (China) in 1994 and 1997, respectively, and then his Ph.D. degree from Virginia Tech in 2001. He has been an Assistant Professor at The University of Tennessee (UT), Knoxville, TN, since August 2005. Prior to joining UT, he worked at ABB, Raleigh, NC, as a senior and then a principal R\&D engineer for four and a half years. His research interests include reactive power, distributed generation, distribution systems, power markets, and reliability. Dr. $\mathrm{Li}$ is the recipient of the 2006 Eta Kappa $\mathrm{Nu}$ Outstanding Teacher Award at UT, voted by undergraduate ECE students. He is a registered Professional Engineer in the State of North Carolina. 